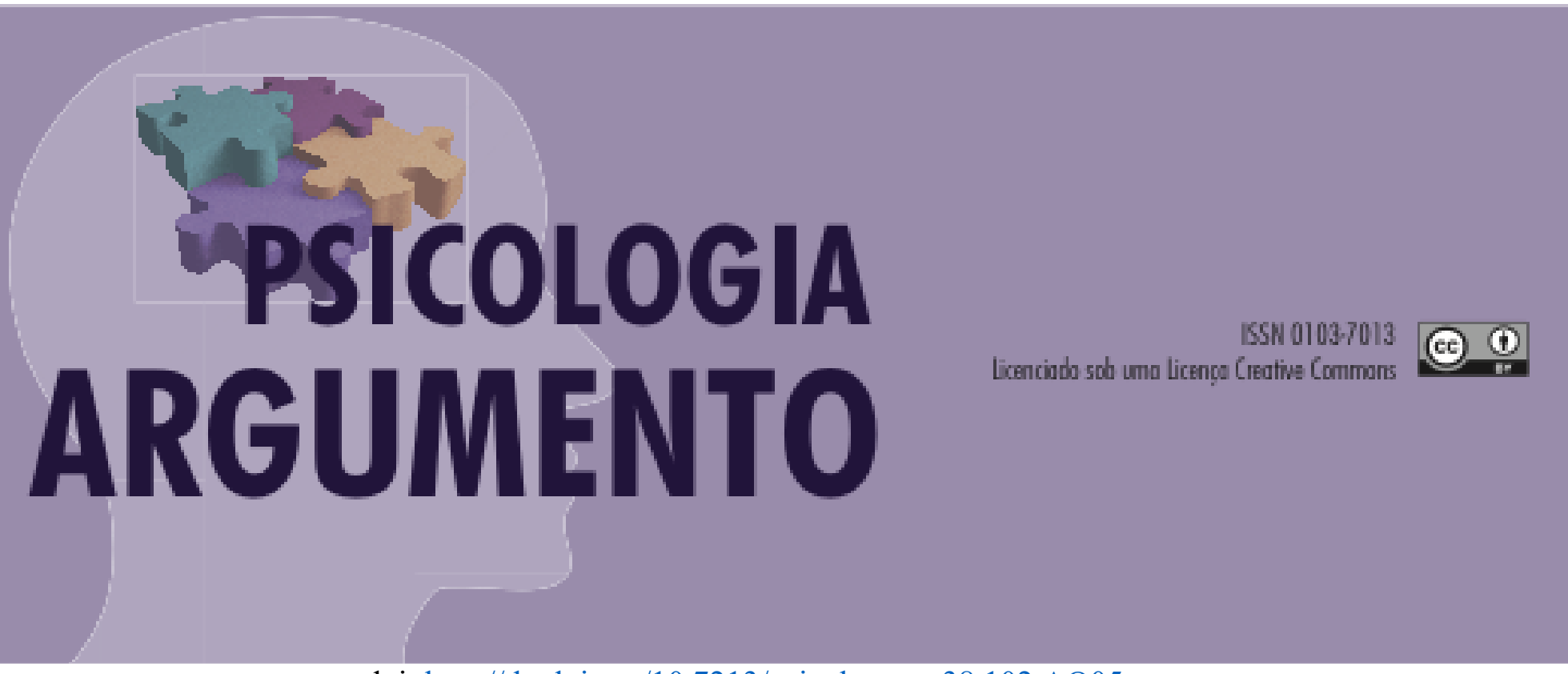

doi: $\underline{\text { http://dx.doi.org/10.7213/psicolargum.38.102.AO05 }}$

\title{
Síndrome do Bebê Sacudido: conhecimento de profissionais de educação infantil
}

Shaken Baby Syndrome: knowledge of early childhood professionals

Síndrome del Bebé Sacudido: conocimiento de los profesionales de la primera infancia

Vanessa Thomazini Cardoso

Universidade Estadual do Centro-Oeste (UNICENTRO), e-mail: cardosvane@gmail.com, orcid: https://orcid.org/0000-0001-5778-6436

Caroline Guisantes de Salvo Toni

Universidade Estadual do Centro-Oeste (UNICENTRO), e-mail:

carolineguisantes@yahoo.com.br, orcid: https://orcid.org/0000-0003-2114-1964

\begin{abstract}
Resumo
No Brasil, há poucas pesquisas sobre a Síndrome do Bebê Sacudido, a qual se caracteriza como uma forma de abuso infantil. Tendo em vista o tempo que muitos bebês passam sob o cuidado de educadoras em instituições escolares, foi objetivo deste estudo avaliar o conhecimento de profissionais que atuam com bebês de 0 a 2 anos a respeito da Síndrome do Bebê Sacudido. Para isso, a partir de aplicação de questionários e de entrevistas investigou-se o conhecimento de 20 educadoras. As entrevistas foram analisadas a partir da técnica de Análise de Conteúdo e o questionário foi avaliado a partir da estatística descritiva e inferencial. De modo geral, os resultados apontam para o desconhecimento das profissionais, dos fatores de risco e de proteção da síndrome, bem como das consequências de sacudir um bebê. Portanto, é necessário que ações de prevenção sejam
\end{abstract}


formuladas para esse contexto, buscando diminuir a incidência desse tipo de violência e buscando um desenvolvimento mais saudável das crianças.

Palavras-chave: Síndrome do Bebê Sacudido; Educação infantil; Escolas maternais

\begin{abstract}
In Brazil, there is little research on Shaken Baby Syndrome, which is characterized as a form of child abuse. In view the time that many babies are taken care for educators in kindergarten institutions, this study aimed to evaluate the knowledge of professionals who work with babies from 0 to 2 years old about Shaken Baby Syndrome. For this, based on the application of questionnaires and interviews, the knowledge of 20 educators was investigated. The interviews were analyzed using the Content Analysis technique and the questionnaire was evaluated using descriptive and inferential statistics. In general, the results point to the lack of knowledge of professionals, the risk factors and protection of the syndrome, as well as the consequences of shaking the baby. Therefore, prevention actions need to be formulated for this context, seeking to reduce the incidence of this type of violence and a healthier development of children.
\end{abstract}

Keywords: Shaken Baby Syndrome; Child Rearing; Schools; Nursery

\title{
Resumen
}

En Brasil, hay poca investigación sobre el síndrome del bebé sacudido, que se caracteriza como una forma de abuso infantil. En vista del tiempo que muchos bebés pasan bajo el cuidado de educadores em instituciones escolares, el objetivo de este estúdio fue evaluar el conocimiento de los profesionales que trabajan con bebés de 0 a 2 años con respecto al Síndrome del Bebé Sacudido. Para ello, a partir de la aplicación de cuestionarios y entrevistas, se investigo el conocimiento de 20 educadores. Las entrevistas se analizaron a partir de la técnica de Análisis de Contenido y el cuestionario se evaluó a partir de estadísticas descriptivas e inferenciales. Em general, los resultados apuntan a la falta de conocimiento de los profesionales, los factores de riesgo y la protección del síndrome, así como las consecuencias de sacudir al bebé. Por lo tanto, es necesario formular acciones de prevención para este contexto, buscando reducir la incidencia de este tipo de violencia y undesarrollo más saludable de los niños.

Palabras clave: Síndrome del bebé Sacudido; Educación Infantil; Guarderías

\section{Introdução}

A Síndrome do Bebê Sacudido (SBS), conhecida como um subtipo do Trauma Craniano Violento (TCV) é uma forma de abuso infantil e refere-se a ferimentos e lesões no crânio, no cérebro e no pescoço, ocasionados de forma intencional (Gordy \& Kuns, 2013; Hinds, Shalaby-Rana, Jackson \& Khademian, 2015). Essa síndrome é causada devido a várias sacudidas violentas ocorridas contra uma criança pequena (Le RouxKemp \& Burger, 2014). Segundo Foley et al. (2013), a cabeça da criança vai para frente 
e para trás, fazendo um movimento tipo chicote, e desse modo, esses movimentos fazem com que o cérebro bata na caixa craniana, ocasionando o rompimento de vasos sanguíneos e ferindo os tecidos cerebrais (Gordy \& Kuns, 2013).

De acordo com Parks, Sugerman, Xu e Coronado (2012) entre os anos de 2003 e 2008 foram calculadas 74.233 internações referentes ao Trauma Craniano Violento nos Estados Unidos. Até o ano de 2013, não havia pesquisas que quantificassem a incidência desse trauma no Brasil (Lopes, 2013).

Referente a nomenclatura da SBS, alguns autores e autoras (Christian, Block \& Committee on Child Abuse and Neglect, 2009; Gordy \& Kuns, 2013; Hinds et al., 2015; Le Roux-Kemp \& Burger, 2014; Narang \& Clarke, 2014; Strouse, 2018), citam a Academia Americana de Pediatria (AAP) afirmando que devido a Síndrome estar relacionada apenas com chacoalhos e sacudidas, torna-se mais adequado a utilização do termo Trauma Craniano Violento (TCV), pois este além de estar relacionado com chacoalhos, também inclui outros maus-tratos que podem ocasionar lesões ao crânio, como puxões, arremessos, quedas, batidas, entre outros. Com isso, ainda segundo os(as) autores(as) citados, a SBS é incluida como um subconjunto do TCV pois só corresponde a uma forma de traumatismo.

Christian et al. (2009) relatam que manter a nomenclatura SBS é muito importante e necessário principalmente quando esta está relacionada com prevenção, visto que os pais podem não possuir o conhecimento que chacoalhar pode ser prejudicial para a criança; ainda, este é um termo mais acessível para a população do que o TCV. Esses autores ressaltam que a AAP reconhece que manter o termo SBS é mais vantajoso quando o objetivo é a prevenção.

Em relação aos sintomas referentes ao TCV, diversos autores (Le Roux-Kemp \& Burger, 2014; Vinchon, 2017; Strouse, 2018) afirmam uma tríade de lesões fundamentais para o diagnóstico: hemorragia subdural, hemorragia da retina e encefalopatia. O primeiro sintoma refere-se a uma hemorragia entre o cérebro e o crânio e o segundo a um pequeno sangramento no olho devido ao rompimento dos vasos da retina (Le Roux-Kemp \& Burger, 2014). Já a encefalopatia refere-se a danos neurológicos, como convulsões, perda de consciência e irritabilidade (Le Roux-Kemp \& Burger, 2014). O estudo de Gordy e Kuns (2013) aponta que lesões menos graves do TCV como irritabilidade, vômitos, letargia, febre e entre outros, são bem mais difíceis de serem relacionadas com o trauma, pois podem indicar outras doenças, logo, são facilmente relacionadas com outras causas. 
Uma equipe de pesquisadores (Nuño et al., 2018) acompanhou aproximadamente 940 crianças diagnosticadas com TCV, até completarem cinco anos idade. Ao início do estudo, os autores observaram as fraturas intracanianas, hemorragia subdural, hemorragia subaracnóidea, edema cerebral e hemorragia retiniana como as lesões mais frequentes relatadas no diagnóstico de TCV. Durante os anos de acompanhamento, os pesquisadores identificaram transtornos comportamentais nas crianças, epilepsia e déficits relacionados com a comunicação, motricidade e com a visão. Além disso, reconheceram atrasos no desenvolvimento e distúrbios de aprendizagem. Estas são, segundo os autores, as principais consequências a longo prazo do TCV. Ademais, esta pesquisa também possibilitou reconhecer que muitas das consequências não são imediatas, por exemplo, a epilepsia aparece frequentemente três meses após a ocorrência do trauma e, danos na comunicação geralmente são evidentes dois anos após a ocorrência da lesão.

Segundo Christian et al. (2009) os danos neurológicos podem ser permanentes, podendo as crianças possuir sequelas para o resto da vida, como: cegueira, retardo mental, paralisia cerebral e dificuldade de aprendizagem. Além disso, o TCV pode também resultar em morte (Christian et al., 2009; Foley et al., 2013; Vinchon, 2017). No entanto, muitos pais não possuem a intenção de machucar seus filhos, mas desconhecem os riscos de sacudi-los.

A SBS geralmente ocorre em momentos em que os(as) cuidadores(as) estão sob influência de sentimentos como estresse e raiva, os quais comumente estão relacionados com o choro infantil e a frustração presente nas tentativas de fazê-lo cessar (Foley et al., 2013; Le Roux-Kemp \& Burger, 2014). Segundo Gordy e Kuns (2013) algumas características como história de violência doméstica sofrida durante a infância, falta de um sistema de apoio, pais solteiros e isolamento social podem ser consideradas como fatores de riscos para a SBS, pois constroem um contexto de maior vulnerabilidade para o adulto cuidador, que aumenta sua probabilidade de cometer algum tipo de abuso.

Além desses fatores, Hennes, Kini e Palusci (2001) apontam que alguns aspectos do bebê como ser menor de um ano de idade, ter nascido prematuro ou com baixo peso também podem ser considerados fatores de risco. Lopes (2013) relata que a SBS ocorre principalmente com crianças menores de um ano de idade, pois a cabeça do bebê é maior e mais pesada que seu corpo. Ainda, a SBS ocorre entre a população em geral, em qualquer classe social e entre todas as etnias. Isso porque, o principal fator de 
risco para a SBS é o choro incessante e a sensação de frustração dos(as) cuidadores(as) (Gordy \& Kuns, 2013; Vinchon, 2017).

Barr (2014) concorda com os referidos autores e ressalta que é a resposta dos(as) cuidadores(as) perante o choro incontrolável do bebê o principal fator de risco, sendo esse sentimento de frustração o responsável pela maior parte dos casos de TCV na primeira infância. Com isso, o autor afirma que o TCV pode ser ocasionado por qualquer pessoa e pressupõe ser importante que a prevenção seja direcionada para a educação sobre o choro como uma forma de comunicação do bebê. Outros autores (Barr, 2014; Christian et al., 2009; Hinds et al., 2015) também relatam a importância da realização de intervenções com pais de recém-nascidos, abordando o padrão de choro normal e também sobre os riscos de sacudir um bebê, pois esses temas geralmente são desconhecidos pelos(as) cuidadores(as).

Sabe-se que o contato, o colo e o ninar são extremamente fundamentais para acalmar um bebê, porém é importante que esses cuidados não ultrapassem um limite e se tornem sacudidas. Caso o(a) cuidador(a) já realizou diversas estratégias para minimizar o choro e ainda assim ele persistir, é importante tanto para o bebê como para quem o está cuidando que ele seja deixado por alguns minutos com outras pessoas que possam estar mais calmas, ou ser deixado sozinho, em local seguro, pois se o bebê não se acalmar e continuar a chorar no colo, as chances do(a) cuidador(a) se sentir estressado(a) e sacudir aumentam (Lopes, 2013; Runyan \& Zolotor, 2009).

Ainda, para Lopes (2013) e Runyan e Zolotor (2009), muitas vezes é a partir do tempo de distanciamento que o bebê e cuidador(a) poderão se acalmar e reestabelecer novamente uma regulação emocional, dado que o choro do bebê é seu principal meio de comunicação, e que é normal um bebê saudável chorar cerca de 2 a 3 horas diárias (Lopes, 2013; Tolliday et al., 2010). Portanto, é necessário que pais e cuidadores tenham o conhecimento sobre o choro e sobre as estratégias que podem ser utilizadas nesses momentos.

Apesar de ser essencial que cuidadores e profissionais que atuam com bebês conhecerem a SBS, essa não é a realidade. Os poucos estudos realizados voltam-se em especial para profissionais de saúde e pais/cuidadores (Gordy \& Kuns, 2013). Em uma breve pesquisa nas bases de dados Scielo, BVS-psi e Lilacs utilizando como descritores "Síndrome do Bebê Sacudido" e "Trauma Craniano Violento" e as combinações "Síndrome do Bebê Sacudido AND prevenção" e "Trauma Craniano Violento AND 
prevenção" e seus correlatos em inglês, foram encontrados 111 artigos, sendo a maioria deles em idioma inglês. A análise desses estudos mostrou que poucos destes discorrem sobre a prevenção da SBS; em sua maioria relatam dados epidemiológicos e pesquisas exploratórias sobre o tema. Nenhum estudo aponta intervenção e orientação realizada com profissionais de áreas distintas da saúde, como a educação, por exemplo.

Em busca de pesquisas brasileiras encontrou-se apenas cinco estudos (Accioly Filho et al., 2017; Fernandes, Silva \& Javorski, 2010; Lopes, 2013; Santana, Silva, Soares, Santana \& Nery, 2017; Vieira, Milbrath \& Moraes, 2006). Dentre eles, destacase a dissertação de Lopes (2013), que é o estudo pioneiro sobre a temática no Brasil. A autora construiu sua dissertação em quatro artigos: 1- uma revisão da literatura nacional e internacional; 2- investigação sobre o conhecimento de pais de recém-nascidos sobre a SBS; 3- crença de pais brasileiros sobre a punição corporal em bebês; 4- avaliação de três materiais informativos para o aumento do conhecimento de pais brasileiros a SBS.

Também foi encontrado o estudo de revisão de literatura não sistemática de Santana, Silva, Soares, Santana e Nery (2017), no qual os autores discutiram sobre o que é o TCV, os sintomas e as consequências, abordando também as principais formas de prevenção. Ainda, o estudo de Accioly Filho et al. (2017) buscou descrever como preveniram as ocorrências de traumatismos cranianos relacionadas a acidentes de trânsito. De acordo com essa pesquisa, eles realizaram campanhas com o intuito de corrigir o comportamento dos pais, reforçando a ideia do uso do cinto de segurança.

Além disso, também se encontrou um relato de experiência de acadêmicas de enfermagem (Vieira, Milbrath \& Moraes, 2006). As autoras relatam sobre suas vivências no contexto de saúde e reforçam a necessidade de intervenções nos contextos de saúde pública, principalmente para a equipe, que precisa de capacitação sobre síndrome, pois é a responsável para atender estes casos. Por último, foi identificada uma pesquisa sobre o conhecimento de uma equipe de Saúde da Família sobre a SBS (Fernandes, Silva \& Javorski, 2010), que também afirma o não conhecimento da equipe em relação a essa forma de violência.

Atualmente são poucas as pesquisas produzidas sobre a temática SBS no país, sendo que somente duas universidades brasileiras trabalham de forma aplicada com o tema. A Universidade Federal de São Carlos (UFSCAR) (Lopes, 2013) e a Universidade Estadual do Centro-Oeste (UNICENTRO) (Souza, Batista \& Toni, 2018). Esta última universidade possui um projeto de extensão com foco na prevenção de maus-tratos 
infantis; nele são realizados grupos com os cuidadores de bebês sobre o desenvolvimento infantil e a SBS.

Internacionalmente, muitos autores afirmam a importância da realização de intervenções com profissionais de saúde, visto que muitos destes desconhecem a SBS. Mas além destes profissionais, também é fundamental a realização de pesquisas e intervenções com profissionais de outras áreas que atuam com bebês, como os que atuam na educação infantil por exemplo.

No Brasil, muitas crianças iniciam nos Centros Municipais de Educação Infantil (CMEI) muito pequenas. É comum que com o final da licença maternidade, quando o bebê tem aproximadamente quatro meses de idade, muitas crianças passem a frequentar alguma instituição infantil, e assim, permanecem o dia com os(as) profissionais. Logo, torna-se fundamental que sejam realizadas pesquisas com essas educadoras, buscando avaliar o seu conhecimento sobre a SBS, seus sinais, padrão de choro normal e estratégias adequadas para o manejo do choro.

Nesse contexto, a presente pesquisa teve como foco principal avaliar o conhecimento de profissionais que atuam com bebês de 0 a 2 anos a respeito da SBS. Dessa maneira, foi possível conhecer o que as profissionais que atuam com bebês sabem sobre o tema e sobre as estratégias utilizadas por elas para o manejo do choro do bebê.

\section{Método}

Esta pesquisa se caracteriza como uma pesquisa exploratória, com método quantiquali, na qual se buscou uma aproximação com o tema de estudo a partir de entrevistas e questionários. O estudo foi realizado em Centros Municipais de Educação Infantil (CMEI) e em escolas privadas de educação infantil em um município de pequeno porte do interior do Paraná. Esta pesquisa teve a aprovação do Comitê de Ética e Pesquisa (CEP) sob o Parecer n. 2.850.168.

\section{Participantes}

As profissionais que participaram da pesquisa foram indicadas por conveniência a partir da disponibilidade de cada CMEI, sendo que o critério de inclusão no presente estudo era atuar com bebês menores de 2 anos de idade e ser maior de 18 anos. Participaram 20 cuidadoras, sendo 10 de instituições públicas e 10 de particulares, as 
quais foram todas mulheres, com idade entre 20 e 67 anos $(M=35,74 ; D P=12,7)$. No âmbito público $20 \%(\mathrm{n}=2)$ das profissionais tinham concluído uma graduação e $50 \%$ $(\mathrm{n}=5)$ possuíam pós-graduação, e a maioria delas $70 \%,(\mathrm{n}=7)$ atuava no cuidado com bebês por cerca de 7 a 9 anos. Já nas instituições particulares $10 \%(n=1)$ tinham concluído a graduação, enquanto que $60 \%(\mathrm{n}=6)$ ainda estavam terminando a graduação e a maioria $40 \%(\mathrm{n}=4)$ atuava na área por 2 e 4 anos.

\section{Instrumentos}

Questionário: composto por questões objetivas sobre o conhecimento da profissional a respeito da Síndrome do Bebê Sacudido, fatores de risco e principais consequências, foi elaborado a partir do questionário de Lopes e Williams (2016). No entanto, houve alterações significativas para abranger o contexto das educadoras que participaram da pesquisa. O questionário foi dividido em dados sociodemográficos e quatro grupos de perguntas. Os dados sociodemográficos abrangeram questões como idade, sexo, escolaridade e tempo de atuação; Os grupos de perguntas se relacionavam a: 1- Situações que possam fazer um bebê chorar; 2- Estratégias de controle do choro do bebê; 3-Atitudes do(a) cuidador(a) prejudiciais aos bebês e 4- Consequências de sacudir o bebê. Os quatro grupos de perguntas foram organizados a partir de uma pergunta inicial e na sequência apresentada algumas afirmações (itens). As cuidadoras deveriam assinalar, em uma escala likert de 5 pontos, qual era a frequência da ação ou a frequência que melhor representava como elas agiriam em cada item, sendo as alternativas "nunca" correspondentes para o número 1, "raramente" para 2, "as vezes" para 3, "quase sempre" para 4 e "sempre" para 5.

Roteiro de entrevista semi-estruturado: abrangeu questões referentes à: a) conhecimento da SBS; b) ao que as participantes já ouviram falar e o que poderiam dizer no momento; c) a quais ações as educadoras acreditavam que causavam a SBS; d) o que o sacudir poderia ocasionar no bebê; e) o que elas fazem no primeiro momento do choro do bebê; f) ao possível nervosismo das educadoras frente ao choro, e g) o que as participantes acham sobre deixar um bebê sozinho, em um local seguro, no momento do choro, após serem verificadas questões de cuidados básicos e de serem realizadas outras estratégias. 


\section{Procedimentos}

Tanto para os CMEIS públicos como para as escolas de educação infantil particulares buscou-se o contato com cada instituição para o conhecimento de sua disponibilidade em participar da pesquisa, bem como para a indicação de possíveis cuidadoras com disponibilidade para participar. Para cada instituição que apresentou interesse houve agendamento do dia e horário adequado para que a coleta de dados pudesse ser efetuada. As profissionais puderam optar por participar da pesquisa respondendo apenas o questionário ou também participando da entrevista. Obteve-se o mesmo número de questionários e entrevistas realizadas para os dois tipos de instituições, assim, totalizou 20 questionários respondidos (10 de instituições públicas e 10 de particulares) e 12 entrevistas efetuadas (seis de instituições públicas e seis de particulares).

O questionário foi avaliado a partir da estatística descritiva e inferencial, a partir do teste U de Mann-Whitney, teste não-paramétrico utilizado para comparação de amostras independentes. Foram comparadas as respostas das participantes a todas as questões dos questionários em função do tipo de instituição em que trabalhavam. Como não se observou diferenças estatisticamente significativas nas respostas quando contrastados os dois grupos, optou-se no presente estudo por analisar todas as participantes como um único grupo. Assim, as respostas das 20 participantes foram analisadas de forma conjunta.

Destaca-se que para a organização dos resultados do questionário, se agrupou os itens referentes a respostas pertencentes a uma mesma classe de comportamentos. Dessa forma, as questões sobre as possíveis causas relacionadas ao choro do bebê, foram agrupadas em dois conjuntos: a) cuidados básicos/fisiológicos do bebê, e b) características temperamentais/comportamentais do bebê. Optou-se por analisar duas questões desse conjunto em separado, "os bebês choram sem motivo" e "o bebê quer colo", devido a importância da informação para compreensão da SBS. Também se agrupou as estratégias de controle do choro em a) necessidades básicas do bebê, e b) relação cuidadora-bebê. Apenas os itens "colocaria o bebê em um local seguro e esperaria para que o mesmo se acalmasse sozinho" e "pediria para alguém mais calmo cuidar do bebê" foram analisados individualmente devido à importância para compreensão da SBS. Para a análise da consistência interna dos itens agrupados, procedeu-se a análise do Alpha de Cronbach, método que permite avaliar o quanto o grupo de itens refere-se a um mesmo 
constructo. Todas as análises foram realizadas a partir do programa SPSS18.0 (Statistical Package for the Social Sciences), versão para Windows.

As entrevistas foram realizadas individualmente, em sala da própria instituição, com os devidos cuidados para o sigilo. Foi utilizado gravador, com a autorização das participantes. Após a transcrição das entrevistas na integra, estas foram analisadas a partir da Análise de Conteúdo (Bardin, 2011). A análise de conteúdo é fundamentada em três fases cronológicas. A primeira é nomeada como pré-análise e consiste na fase de organização dos dados, e na realização de uma leitura flutuante dos materiais. Além disso, nesta fase também há a formulação de hipóteses e objetivos e a preparação do material coletado. A segunda fase é referente a exploração do material e, a terceira, consiste no tratamento dos resultados, na inferência e na interpretação dos dados, o qual compõe o corpus desse trabalho (Bardin, 2011).

\section{Resultados}

Inicialmente serão apresentados os resultados referentes às respostas das educadoras ao questionário, analisadas a partir de estatística descritiva e inferencial. $\mathrm{Na}$ sequência, serão apresentados os resultados da Análise de Conteúdo das entrevistas.

A comparação das respostas das participantes aos questionários, contrastando-se instituição públicas e privadas a partir do teste U de Mann-Whitney, não demonstrou diferença estatisticamente significativa às questões de choro $(U=50,00 ; p=1,00)$, conhecimento da SBS e demais itens do questionário (U-45,00; $\mathrm{p}=686$ ). Assim, optouse pela análise conjunta das respostas das 20 profissionais.

Em relação ao tempo de choro do bebê, a maioria das participantes 90\% $(\mathrm{n}=18)$ afirmou ser normal um bebê saudável chorar de 1 a 2 horas por dia. Apenas duas profissionais assinalaram a opção de 2 a 3 horas diárias. Referente ao conhecimento da SBS, $70 \%(n=14)$ profissionais afirmam conhecer a Síndrome.

O primeiro grupo de questões do questionário refere-se a causas relacionadas ao choro do bebê. Os doze itens que compuseram essa parte do questionário foram agrupados e analisados em função de: 1- relação aos cuidados básicos/fisiológicos do bebê e 2aspectos comportamentais e temperamentais. Destaca-se que foi realizada a análise da consistência interna do agrupamento dos itens a partir do Alpha de Cronbach; os valores encontrados (acima de 0,7) indicam a confiabilidade do agrupamento. Como pode ser 
observado na Tabela 1, a partir da média de cada agrupamento de itens (que poderia atingir no máximo 5 pontos de média), os cuidados relacionados com questões fisiológicas e básicas dos bebês obtiveram média mais alta; desse modo, pode-se inferir que elas acreditam que o choro está mais relacionado com esses aspectos.

\section{Tabela 1}

Possíveis causas relacionadas ao choro do bebê

\begin{tabular}{|c|c|c|c|c|}
\hline $\begin{array}{c}\text { Agrupamento de } \\
\text { itens }\end{array}$ & Causas & $\begin{array}{l}\text { Alpha de } \\
\text { Cronbach }\end{array}$ & $\begin{array}{c}\text { M } \\
\text { dos } \\
\text { itens }\end{array}$ & Dp \\
\hline $\begin{array}{c}\text { Cuidados básicos/ } \\
\text { fisiológicos do } \\
\text { bebê }\end{array}$ & $\begin{array}{l}\text { O bebê está com fome }(M=4,25 \mathrm{Dp}=0,78) \\
\text { Está com dor }(\mathrm{M}=4,15 \mathrm{Dp}=1,04) \\
\text { O bebê está doente }(\mathrm{M}=3,65 \mathrm{Dp}=0,87) \\
\text { Está com a fralda suja }(\mathrm{M}=3,42 \mathrm{Dp}=1,21) \\
\text { O bebê está cansado }(\mathrm{M}=3,21 \mathrm{Dp}=0,97)\end{array}$ & 0,75 & 3,75 & 0,68 \\
\hline $\begin{array}{c}\text { Características } \\
\text { temperamentais/ } \\
\text { comportamentais } \\
\text { do bebê }\end{array}$ & $\begin{array}{l}\text { Está entediado }(M=3,25 \mathrm{Dp}=1,16) \\
\text { O bebé é mimado }(M=3,21 \mathrm{Dp}=1,27) \\
\text { É impaciente }(M=3 \mathrm{Dp}=1,15) \\
\text { Está triste }(M=2,9 \mathrm{Dp}=1,41) \\
\text { É genioso }(\mathrm{M}=2,7 \mathrm{Dp}=1,17) \\
\text { É muito exigente }(\mathrm{M}=2,7 \mathrm{Dp}=1,41) \\
\text { É mal comportado }(\mathrm{M}=2,2 \mathrm{Dp}=1,39)\end{array}$ & 0,87 & 2,85 & 0,91 \\
\hline
\end{tabular}

Além dos itens apresentados na Tabela 1, dois itens desse agrupamento de questões do questionário foram analisados separadamente, tendo em vista sua importância para a compreensão dos fatores de risco associados a SBS. O primeiro foi "os bebês choram sem motivo", o qual teve média de 1,8 e desvio padrão de 1,15. Esse dado aponta que em geral as cuidadoras acreditam que quando as crianças choram é porque algo de errado está acontecendo. Além disso, o item “o bebê quer colo" teve média 3,75 e desvio padrão de 0,71 .

O segundo grupo do questionário, composto por 10 itens, referia-se às estratégias utilizadas pelas profissionais para controle do choro do bebê, o qual também foi agrupado em torno de duas classes de comportamento, sendo 1- relacionado às necessidades básicas do bebê, e 2- referentes à relação da cuidadora/bebê. Desse modo, pode-se perceber pela média, apontada na Tabela 2, que a maioria das profissionais, em momentos de choro das crianças, procura realizar atividades e estratégias relacionadas à interação cuidadora/bebê, buscando alternativas criativas. 


\section{Tabela 2}

Estratégias utilizadas para controle do choro do bebê

\begin{tabular}{|c|c|c|c|c|}
\hline $\begin{array}{c}\text { Agrupamento } \\
\text { de itens }\end{array}$ & Ações & $\begin{array}{l}\text { Alpha de } \\
\text { Cronbach }\end{array}$ & $\begin{array}{c}\text { M } \\
\text { dos } \\
\text { itens }\end{array}$ & Dp \\
\hline $\begin{array}{l}\text { Necessidades } \\
\text { básicas do bebê }\end{array}$ & $\begin{array}{l}\text { Alimentaria o bebê }(M=3,6 \mathrm{Dp}=0,94) \\
\text { Trocaria a fralda }(\mathrm{M}=3,58 \mathrm{Dp}=1,12) \\
\text { Trocaria a roupa }(\mathrm{M}=3 \mathrm{Dp}=1,12)\end{array}$ & 0,85 & 3,39 & 0,92 \\
\hline $\begin{array}{l}\text { Relação } \\
\text { Cuidadora- } \\
\text { bebê }\end{array}$ & $\begin{array}{l}\text { Distrair o bebê, com brinquedos e } \\
\text { coisas do ambiente }(M=4,42 \mathrm{Dp}=0,76) \\
\text { Cantar }(\mathrm{M}=4,4 \mathrm{Dp}=0,75) \\
\text { Colocar música }(\mathrm{M}=4,3 \mathrm{Dp}=0,8) \\
\text { Abraçar }(\mathrm{M}=4,15 \mathrm{Dp}=1,18) \\
\text { Passear com o bebê }(\mathrm{M}=4 \mathrm{Dp}=0,91) \\
\text { Ninaria o bebê }(\mathrm{M}=3,9 \mathrm{Dp}=0,91) \\
\text { Fazer massagem }(\mathrm{M}=3,65 \mathrm{Dp}=1,13)\end{array}$ & 0,71 & 4,13 & 0,53 \\
\hline
\end{tabular}

Além dos itens apresentados na Tabela 2, dois itens desse agrupamento de questões do questionário foram analisados separadamente. Em relação a "colocaria o bebê em um local seguro e esperaria para que o mesmo se acalmasse sozinho", a média foi de 1,55 e o desvio padrão de 0,68 ; destaca-se ser uma média bastante baixa, visto a escala variar de 1 a 5 . Também se observou uma média baixa em relação a "pediria para alguém mais calmo cuidar do bebê", sendo esta de 1,9 e desvio padrão de 1,16. Essas questões também podem assinalar fatores de risco para o bebê e para a ocorrência da SBS.

O terceiro grupo de questões abordou algumas atividades do dia a dia. As profissionais responderam sobre a probabilidade de prejuízos que essas ações poderiam oferecer para os bebês. A escala variou de 1 a 5, onde assinalava-se 1 para as atividades que continham menores probabilidades de ocasionar riscos para os bebês e 5 para aquelas que continham maiores probabilidades de prejuízos. 


\section{Tabela 3}

Avaliação de risco de atividades para os bebês segundo as profissionais de educação

\begin{tabular}{lcc}
\multicolumn{1}{c}{ Atividades } & Média & Dp \\
\hline $\begin{array}{l}\text { Colocar o bebê no berço rapidamente deixando que o peso } \\
\text { do corpo caia sobre o colchão }\end{array}$ & 4,58 & 1,12 \\
$\begin{array}{l}\text { Segurar o bebê pelos bracinhos e erguê-lo rapidamente, } \\
\text { para brincar com ele, fazendo com que ele ria }\end{array}$ & 4,53 & 0,77 \\
$\begin{array}{l}\text { Deixar o bebê chorando sozinho, mesmo estando em um } \\
\text { local seguro, e que você já volte para atendê-lo }\end{array}$ & 4,37 & 1,25 \\
$\begin{array}{l}\text { Balançar/chacoalhar o bebê até que ele pare de chorar } \\
\text { Colocar um filme infantil para o bebê assistir, por alguns }\end{array}$ & 4,26 & 1,32 \\
minutos & 1,79 & 1,22 \\
$\begin{array}{l}\text { Dar chupeta para o bebê se acalmar } \\
\text { Mostrar coisas novas para o bebê, como brinquedos e livros }\end{array}$ & 1,05 & 0,22 \\
\begin{tabular}{l} 
Brincar no chão com o bebê, sob um tapete confortável \\
\hline
\end{tabular} & 1,00 & 0,00 \\
\hline
\end{tabular}

A partir da Tabela 3, pode-se perceber que algumas atividades tiveram médias baixas, sendo consideradas atividades com menores riscos. Por outro lado, outras atividades apresentaram médias significativamente alta, como "deixar o bebê chorando sozinho, mesmo estando em um local seguro" e "balançar/chacoalhar o bebê até que ele pare de chorar”. Desse modo, estas atividades são caracterizadas pelas participantes como prejudiciais.

A quarta e última parte do questionário referia-se a perguntas mais precisas sobre o conhecimento das profissionais a respeito da Síndrome do Bebê Sacudido. Nela podese avaliar o que as profissionais acreditam que pode acontecer com um bebê se ele for sacudido. Na Tabela 4, o $\mathrm{N}$ representa a quantidade de profissionais que responderam cada questão, uma vez que algumas profissionais optaram por não responder a algumas questões. 


\section{Tabela 4}

Conhecimento das profissionais sobre o que pode acontecer com um bebê se ele for sacudido

\begin{tabular}{llcc}
\hline $\begin{array}{l}\text { O que pode acontecer com o bebê se ele for } \\
\text { chacoalhado/sacudido }\end{array}$ & $\mathbf{N}$ & Média & Dp \\
\hline O bebê pode ter problemas com a fala & 14 & 4,29 & 1,06 \\
O bebê pode ter problema de visão & 14 & 4,07 & 1,14 \\
O bebê pode ter problemas futuros, como de & 18 & 4,00 & 1,13 \\
aprendizagem & 19 & 3,95 & 0,97 \\
O bebê pode vomitar & 16 & 3,94 & 1,12 \\
O bebê pode ter problemas físicos e mentais & 20 & 3,70 & 1,03 \\
O bebê chora mais & 15 & 3,67 & 1,44 \\
O bebê pode ter convulsões & 15 & 3,67 & 1,29 \\
O bebê pode não conseguir se alimentar & 15 & 3,47 & 1,59 \\
O bebê pode ter uma parada cardíaca & 16 & 3,31 & 1,53 \\
Pode levar a morte do bebê & 20 & 2,45 & 1,43 \\
O bebê fica alegre e sorri & 20 & 1,95 & 1,09 \\
O bebê fica mais tranquilo & 16 & 1,56 & 1,03 \\
Nada & & &
\end{tabular}

A partir da Tabela 4 pode-se observar que uma quantidade significativa de profissionais optou por não responder algumas questões, sendo que a maioria delas afirmou que não tinham conhecimento sobre as consequências da SBS, logo, não sabiam se posicionar na questão. Seis participantes escreveram "não sei” ao lado de algumas dessas questões.

Em relação às entrevistas, emergiram da análise três grandes temas, a partir dos quais algumas categorias foram construídas. Buscou-se ilustrar com falas das participantes cada uma das categorias.

O primeiro tema referiu-se ao:

1- Conhecimento e consequências da SBS: Esse tema diz respeito ao conhecimento das profissionais sobre a SBS. Aqui estão reunidas as percepções das cuidadoras sobre a síndrome, relatos sobre o que já ouviram falar e o que entendiam sobre as causas e consequências da SBS.

1.1- Não conhecimento da SBS ou conhecimento superficial: A maioria das participantes afirmou que nunca ouviu falar na síndrome, relatando ser um assunto novo. 
Outras afirmaram que já tinham visto/estudado a síndrome, mas de maneira geral e informal, por meio de profissionais de saúde, ou por meio das mídias sociais. Dessa forma, nenhuma profissional relatou ter vivenciado formação, em nível técnico ou acadêmico, que tratava da SBS.

Totalmente novo pra mim, nunca ouvi falar (P03, novembro de 2018).

Na verdade eu tive contato através da internet, que eu vi tipo no facebook colocarem algumas coisas, ai eu entrei e dei uma lida, mas aquela coisa básica assim, sabe (P01, novembro de 2018).

Já ouvi falar [...] na Unicentro, no dia em que levei meus filhos pra fazerem o teste da orelhinha (P04, novembro de 2018).

1.2- A associação do sacudir como algo prejudicial: No momento de relatar sobre a SBS, a maioria afirmava que não a conhecia, mas todas as participantes afirmaram que sacudir um bebê pode causar danos a este. Mesmo não sabendo quais danos seriam, todas afirmaram a prática como prejudicial e a maioria relacionou a danos neurológicos.

A, assim, a gente sabe que não pode né, mas assim, o que resulta ou o que acontece se sacudir a criança, até numa brincadeira, alguma coisa assim né, não tenho noção no que pode acontecer (P11, abril de 2019).

Eu não tenho noção exatamente do que é, mas sei que faz mal para o bebê, por que nem uma pessoa adulta se você pegar ela e ficar chacoalhando ela, ela vai ficar mal, então por que que um bebê vai ficar bem [...](P02, novembro de 2018).

Sei que pode ser alguma coisa prejudicada no cérebro, alguma coisa assim, não sei (P08, março de 2019).

1.3- Falta de conhecimento das ações que podem causar a síndrome: algumas participantes afirmaram não conhecer quais ações podem causar a SBS além do sacudir.

Agora você me pegou, porque a gente conhece muito pouco sabe [...] acho que seria isso né, sacudir o bebê (P05, novembro de 2018).

1.4- Ocorrência da SBS a partir de movimentos bruscos: essa categoria referese às respostas que dizem sobre a SBS acontecer devido a algum impacto, seja erguer a criança com muita velocidade, ou soltá-la em algum lugar rapidamente, como também em brincadeiras, ou a forma de pegar ou carregar a criança e até ninar o bebê realizando movimentos mais fortes. Apenas duas participantes relacionaram também com acidentes ou batidas de carro. 
É, a gente soltar a criança, a cabeça chegar antes que o corpo em algum local né, ele mexe né, onde ainda eles ainda não estão com os músculos bem fortalecidos né. Então pode causar também o problema (P04, novembro de 2018).

Eu acho que de repente num impacto em um acidente de carro, mesmo a criança estando na cadeirinha talvez o pescocinho vai jogar a cabecinha pra frente e vai sacudir (P07, março de 2019).

1.5- Consequências negativas de sacudir um bebê: a maioria das participantes afirma não saber o que acontece com uma criança que é sacudida. Algumas educadoras se referiram a danos no cérebro do bebê, que podem ocasionar danos futuros como na aprendizagem, na audição, na visão, entre outras.

Ai não sei, eu sempre fazia isso, e aí um dia a mãe disse: não faz isso que machuca e já ouvi casos assim, só que também nunca fui pesquisar na verdade o que era bem certo (P08, março de 2019).

[...] mas talvez afetar alguma parte do cérebro que vai estar sacudindo e batendo e ai não vai poder saber também o que isso afeta né? A fala, audição, parte motora, eu acredito que possa ter um desmaio, e eu acredito que possa até desnucar a criança se for violento (P07, março de 2019).

O segundo grande tema referiu-se a:

2- Estratégias de manejo do choro do bebê: Este agrupamento se refere às estratégias que as profissionais utilizam no momento do choro do bebê, sobre o que elas fazem e acreditam ser adequado. Também foi questionado sobre o que elas achavam sobre deixar um bebê sozinho, em local seguro, para que ele se acalme.

2.1- Pegar no colo, uma estratégia de cuidado no momento do choro: quase todas as profissionais afirmaram que a primeira coisa que elas fazem quando um bebê chora é pegá-lo no colo.

No primeiro momento eu vou lá e pego ele né, se ele estiver ali na cadeirinha ou em algum lugar eu pego ele [...] (P09, março de 2019).

Em primeiro momento a gente pega a criança no colo (P01, novembro de 2018).

2.2- Verificação dos cuidados básicos do bebê: nesta categoria é possível observar que no momento do choro do bebê, elas verificam questões como a fome, a fralda, o sono e se está com alguma dor ou febre. Isso é utilizado como uma estratégia de identificar se há algo de errado ou de incômodo para o bebê. 
Normalmente a gente vai verificar se ele está com cocô, com xixi, a fraldinha deles né? Aí depois vai vendo né? Se não se acalmou, ver se está com fome, e por aí vai né? (P06, novembro de 2018).

\section{3- Estratégias de interação com a criança, uma possibilidade para acalmar:}

esta categoria se refere as estratégias utilizadas no momento do choro que se relacionam com a interação cuidadora-bebê. Elas afirmam, por exemplo, que buscam distraí-lo, cantar músicas, realizar brincadeiras, conversar e entre outras coisas.

Tento distraí-lo com alguma coisa, ou com música, ou com brincadeiras, ou eu levo ali no solário, eu tento distraí-lo (P03, novembro de 2018).

2.4- Deixar o bebê sozinho é uma prática inadequada: a maioria das profissionais afirmou não ser correto deixar uma criança sozinha para que ela se acalme, mesmo que em local seguro e depois de todas as outras estratégias serem realizadas. Muitas delas demonstraram expressões de espanto no momento da pergunta.

Não, totalmente contra, bebê não pode ficar sozinho momento algum, jamais bebê fica sozinho, até mesmo dormindo, o bebê tá no berço, tá dormindo ele é assistido por uma profissional (P12, abril de 2019).

2.5- Deixar o bebê sozinho é uma prática adequada: apenas duas profissionais relataram que deixar a criança sozinha pode ser uma estratégia para lidar com o choro. Outras duas participantes afirmam que utilizam a estratégia de deixar o bebê sozinho para algumas crianças, que nem para todas as crianças "funciona".

É a gente sempre deixa né. Que nem os nossos que são um pouquinho maiorzinhos e se eles começam a chorar e a gente tenta acalmar, alguma coisa, a gente fala, ó vai ficar um pouquinho aqui sentadinho esperando passar[...] (P08, março de 2019).

Então, tem uma menina aqui, que às vezes quando eu tô muito apurada com os demais alunos e tá muito tumultuado, eu faço isso, porque ela tem a chupeta e o cobertor. Mas é essa única criança, que funciona isso, com os demais não, eu pego ela no colo, coloco no bercinho, com o cobertorzinho e com o bico e imediatamente ela se acalma (P03, novembro de 2018).

O terceiro tema referiu-se a:

3- Vivências das cuidadoras frente ao choro do bebê: Nesse tema reuniu-se o relato das sensações e percepções das cuidadoras quanto ao choro do bebê. Foi questionado se 
elas acreditam que ficam nervosas com o choro, e o que elas fazem e/ou podem fazer caso fiquem.

3.1- Não nervosismo perante o choro do bebê: as participantes afirmam que é difícil delas ficarem nervosas, pois já estão acostumadas com o choro dos bebês. Há falas que indicam até um caráter de incompetência quando alguma profissional fica nervosa com o choro.

Mas sabe que eu acho que nunca precisei chamar alguém, para cuidar de um bebê, sou calma para essas coisas, precisamos preparar o ouvido para essas coisas, se você ficar dentro de uma sala com muitas crianças chorando e você ficar estressado você tem que mudar de serviço (P02, novembro de 2018).

3.2- Nervosismo relacionado ao choro do bebê: algumas participantes afirmam que ficam e/ou que podem ficar nervosas e ansiosas com o choro do bebê, principalmente por não saberem como fazê-lo cessar. Porém, duas profissionais relataram que podem ficar nervosas com o choro, mas que não possuem possibilidade de sair, tomar um ar, ou pedir ajuda para alguém, pois são as únicas responsáveis por uma turma.

Até porque daí como a gente tá ali naquele momento, naquela tensão, a gente precisa dar uma descansada, tomar uma água, se acalmar, pra voltar na sala pra atender o bebê (P09, março de 2019).

Porque eu acredito que dependendo do estado que a gente se encontra, pode transmitir sim pra criança, pro bebê, e com certeza, se eu tivesse a possibilidade de sair um pouco, espairecer, ou entregar o bebê para uma outra pessoa que esteja em situação mais calma, com certeza (P03, novembro de 2018).

\section{Discussão}

Em um contexto em que a mulher mãe precisa voltar ao trabalho quando seu bebê tem em torno de 4 a 6 meses, é com as profissionais de educação infantil que a maioria dos bebês passa a maior parte do dia. Com isso, é importante que estas educadoras conheçam a SBS, tanto para poderem evitar que esse maus-tratos aconteça, quanto para ajudar a identificá-lo. No entanto, os resultados do presente estudo apontam para a falta de conhecimento das profissionais em relação a SBS, seus fatores de risco e proteção, bem como das suas consequências. 
Os dados observados através dos questionários e entrevistas demonstraram que educadoras de instituições públicas e particulares não conhecem, ou conhecem muito superficialmente a SBS. Mesmo as educadoras de instituições públicas, as quais possuem mais experiência no cuidado com bebês e formação acadêmica desconhecem a síndrome, o que aponta na direção de que temas como prevenção de maus-tratos e manejo de choro não fazem parte da formação acadêmica e/ou técnica das profissionais. A maior parte das participantes afirma ter ouvido falar no termo, mas no momento de discorrer brevemente sobre o que sabem sobre a síndrome, a maioria não conseguiu formular uma resposta. Também, na mesma direção das respostas às entrevistas, nas respostas à questão do questionário sobre as consequências da SBS, várias profissionais optaram por não a responder; além disso, seis delas ressaltaram que não sabiam.

Entre os fatores de risco para a SBS avaliados no presente estudo está o conhecimento de padrão de choro do bebê. Em relação a esse, a maior parte das educadoras afirmou que os bebês choram cerca de 1 a 2 horas por dia, sendo que segundo estudos (Lopes, 2013; Tolliday et al., 2010), é normal um bebê saudável chorar de 2 a 3 horas diárias. Segundo diversos autores (Gordy \& Kuns, 2013; Lopes, 2013; Vinchon, 2017), o choro se configura como o principal fator de risco para a SBS.

A falta de conhecimento da SBS e dos padrões de choro do bebê é um contexto que pode configurar um fator de risco para a ocorrência da mesma, pois a frustração das(os) cuidadoras(es) presente nos momentos de choro do bebê pode aumentar as chances de ocasionar a SBS. Sabe-se que no momento do choro incessante, a angústia de fazê-lo parar é presente e, muitas vezes, uma estratégia utilizada é o sacudir (Barr, 2014; Gordy \& Kuns, 2013; Vinchon, 2017). Além disso, Barr (2014) descreve que o sacudir pode ser usado para cessar o choro, visto que quando se sacode o bebê, este tende a parar de chorar; o comportamento da(o) cuidadora é reforçado, e a probabilidade de sacudir outras vezes aumenta.

Porém, a falta de conhecimento sobre o tema parece abranger todas as áreas, inclusive a de saúde. Um estudo realizado no Brasil (Fernandes et al., 2010) investigou o conhecimento de 142 profissionais de saúde, de Unidades de Saúde da Família, sobre a SBS. De acordo com a pesquisa, 97\% dessas pessoas não conheciam a síndrome, e, além disso, cerca de 60,8\% desses profissionais afirmaram já ter sacudido um bebê. Desse modo é perceptível que se nem os(as) profissionais de saúde, os quais são reconhecidos como os mais importantes profissionais envolvidos na prevenção e diagnóstico da SBS 
conhecem a síndrome, os profissionais de educação infantil não a conhecerem não surpreende.

Outro ponto em que os dados das entrevistas e questionários convergem é sobre as crenças das profissionais a respeito das possíveis causas do choro do bebê. Observouse que a maioria das educadoras afirmou que o choro estava relacionado aos cuidados básicos/fisiológicos do bebê, como fralda suja, fome, estar doente, com dor, entre outros. Além disso, uma média significativamente baixa de profissionais afirma que um bebê chora "sem motivo" diretamente detectável, o que também configura um fator de risco. Isto porque, como já mencionado, o choro é algo natural, podendo o bebê chorar sem motivo aparente, pois o choro pode ser uma resposta natural do organismo, podendo o bebê estar apenas cansado. Devido a isso, é importante que as profissionais conheçam o padrão de choro normal de um bebê saudável.

Ainda, houve uma média alta das profissionais que afirmaram que um dos motivos do choro do bebê é ele querer colo. Certamente isso não afirma que a SBS ocorra, mas também é um dado a ser observado, pois possivelmente elas já procuram niná-lo ou segurá-lo no colo, podendo a ocorrência da SBS estar mais próxima de acontecer, se o choro persistir. Nas entrevistas também se observou que uma das ações perante o choro infantil é pegar a criança no colo. Certamente o colo e o ninar são fundamentais e podem acalmar um bebê, porém o que se ressalta aqui é o cuidado necessário para que não se ultrapasse o limite do ninar para o sacudir. caso o bebê não se acalme e continue a chorar no colo, aumentam-se as chances do(a) cuidador(a) se sentir estressado(a) em relação ao choro e sacudir o bebê (Lopes, 2013).

Além disso, pode ser observado que muitas das profissionais acreditam que deixar o bebê sozinho em local seguro em momentos de muito choro se caracteriza como uma estratégia inadequada. Nas respostas ao questionário, deixar o bebê sozinho em local seguro obteve uma média alta demonstrando ser uma prática compreendida pelas profissionais como prejudicial ao bebê. Nessa mesma direção, na entrevista, muitas demonstraram indignação no momento da pergunta, afirmando até que era uma prática perigosa. Isso pode estar associado à formação das cuidadoras, que orienta fortemente ao cuidado e atenção ao bebê durante todo o tempo, especialmente quando se trata de instituição infantil. Sabe-se que deixar o bebê chorando não deve ser a primeira opção de um(a) cuidador(a); essa prática só é indicada caso o bebê chore excessivamente e se torne um fator estressante para o(a) cuidador(a)e, consequentemente, um risco para a 
ocorrência da síndrome (Barr, 2014; Lopes, 2013; Runyan \& Zolotor, 2009). Porém, compreende-se que é importante discutir e promover reflexões com os cuidadores sobre esses momentos de estresse e as alternativas de cuidado.

É nesse contexto que diversos estudos (Foley et al., 2013; Le Roux-Kemp \& Burger, 2014; Lopes, 2013; Runyan \& Zolotor, 2009) apontam para a importante estratégia dos cuidadores deixarem o bebê em local seguro e se afastarem por alguns momentos em caso de choro incessante. Desse modo, é importante que as cuidadoras saibam que tanto elas quanto o bebê podem precisar ter um tempo para se autorregular emocionalmente. Nesse sentido, é necessário trabalhar a visão da instituição sobre o comportamento do choro do bebê, construindo instruções claras sobre condutas das profissionais diante do mesmo.

Ainda, apenas uma minoria das cuidadoras afirmou que pediria para outra pessoa mais calma ficar com o bebê em momentos de choro incessante. Tal conduta pode ser um fator de risco para a SBS ocorrer. Lopes (2013) descreve que o contato físico é indicado apenas quando o(a) cuidador(a) estiver calmo(a) e paciente. Porém, muitas das profissionais afirmaram que não ficam nervosas diante do choro dos bebês, o que vai de encontro a literatura, a qual descreve que o estresse perante o choro é algo normal e natural, principalmente se este estiver sendo incontrolável (Barr, 2014; Lopes, 2013).

Frente a esses dados, três hipóteses podem ser levantadas sobre esses resultados: 1- a de que as cuidadoras não observam/reconhecem suas emoções frente ao choro; 2que elas se habituem ao chorar das crianças e não respondem responsivamente a isso e 3que pode ser um tema que tenham alguma dificuldade de admitir, devido a construção social do que é ideal ou não no cuidado com crianças. Deve-se levar em consideração a possibilidade de elas buscarem se mostrar competentes aos olhos da pesquisadora e, para tanto, indicam que não se sentem estressadas diante do choro, buscando passar uma imagem de melhores profissionais.

Em qualquer uma das direções que se caminhe, segundo Runyan e Zolotor (2009), é necessário que os(as) cuidadores(as) identifiquem seus sentimentos para que possam lidar de maneira adequada com os mesmos. Ainda, os resultados descrevem um contexto no qual entrar em contato com emoções não é reforçado, podendo inclusive ser punido. Desse modo, é importante que intervenções possam ser realizadas tanto focando na aceitação e reconhecimento do estresse como uma resposta natural frente ao choro do 
bebê, quanto em estratégias de manejo de emoções e do comportamento da cuidadora e do bebê.

Porém, as poucas profissionais que reconhecem que ficam nervosas não possuem apoio ou alguém para poder cuidar do bebê por alguns minutos e/ou auxiliá-las em momentos de choro incessante do bebê, se configurando assim, outro fator de risco para a SBS. Atualmente, a organização dos grupos infantis nos CMEIs no Paraná é definida pela relação professor/criança, sendo que uma profissional pode ficar responsável por uma das seguintes colocações: 1- até seis crianças de até um ano; 2- até oito crianças de um a dois anos; 3- até doze crianças de dois a três anos; 4- até quinze crianças de três a quatro anos; 5- até vinte crianças de quatro e cinco anos (Conselho Estadual de Educação do Estado do Paraná, 2014). Dessa forma, é visto que a legislação faz a descrição de quantas crianças ficam sob responsabilidade de uma profissional, mas não existe a obrigatoriedade de ter uma cuidadora auxiliar, e assim, na maioria das vezes, as profissionais possuem grande sobrecarga de trabalho, algumas precisando atuar sozinhas e responsáveis por um grande número de bebês.

Ainda, os resultados indicam a necessidade de ações que levem a práticas voltadas a prevenção da SBS com cuidadoras da educação infantil. De acordo com alguns autores (Foley et al., 2013; Gordy \& Kuns, 2013; Lopes, 2013), os projetos de prevenção devem atuar de forma a difundir estas informações, pois a falta de conhecimento da síndrome pode aumentar as chances de ela ocorrer. Assim, pode-se perceber a importância de se realizar intervenções sobre SBS, com as instituições infantis de maneira geral, com profissionais e com pais de bebês, tendo em vista que também é a partir de tecnologias leves em saúde que esse tipo de violência pode ser evitado.

Além disso, os resultados da presente pesquisa apontam que muitas das participantes não conhecem quais outras ações, além do sacudir, podem causar lesões. Como a síndrome é caracterizada como um subconjunto do TCV (Christian et al., 2009), outras atitudes como arremessos, batidas, acidentes de carro, e impactos também devem ser trabalhados nas intervenções, pois também podem causar consequências negativas ao desenvolvimento do bebê.

\section{Considerações finais}

No Brasil ainda são poucas pesquisas realizadas sobre a SBS, principalmente aquelas que visam sua prevenção. Visto a importância de se realizar estudo nessa área, o 
presente estudo buscou pesquisar o conhecimento de profissionais de educação infantil sobre a síndrome. Como elas são pessoas que passam muito tempo no cuidado com os bebês, é fundamental que conheçam a SBS, tanto para não cometerem essa forma de maus-tratos, como para poder observar sintomas que possam indicar seu diagnóstico. Compreende-se ainda que tais profissionais podem transmitir informações sobre a SBS e estratégias de manejo de choro do bebê aos pais e cuidadores(as), configurando-se assim como possíveis agentes de prevenção da SBS. Visto os resultados do presente estudo, é de grande importância que ações visando a prevenção da SBS, voltadas a esse público, sejam formuladas. Tais ações podem contribuir para uma diminuição dessa violência contra bebês, construindo condições para um desenvolvimento mais saudável das crianças.

Por tratar-se de um estudo exploratório, torna-se importante destacar algumas limitações do estudo, como ter sido realizado em um município de pequeno porte, com número pequeno de participantes, o que diminui suas possibilidades de generalização. Ainda, a metodologia de entrevistas e questionário respondido presencialmente são limitadores importantes. Para pesquisas futuras, sugere-se a aplicação do questionário online e anônimo, alcançando mais participantes, bem como a realização de grupos focais, buscando que no grupo possam ser elaboradas e conhecidas de forma mais dinâmica as rotinas e práticas de instituições infantis, bem como crenças e comportamentos das cuidadoras sobre o desenvolvimento e choro do bebê.

De maneira geral o presente estudo apresenta contribuições importantes para o campo de pesquisa, como possuir foco no conhecimento das profissionais de educação infantil sobre a SBS, acrescentando pontos significativos e iniciais para intervenções futuras. Um desses pontos seria a possibilidade de treinamento e oficinas para essas profissionais, além de propostas de inserção nos currículos de formação de professores, a discussão sobre a SBS e maus-tratos. Ainda, apontar a necessidade de se trabalhar com essas profissionais o desenvolvimento de regulação e manejo das emoções. Além disso, a pesquisa contribuiu para um levantamento inicial que demonstra o desconhecimento da SBS por parte das cuidadoras, bem como apresenta as condições organizacionais desfavoráveis a práticas preventivas.

\section{Referências}


Accioly Filho, M. A. A., Cunha, K. L., Costa, L. M., Oliveira, L. L., Moraes, K. T. S. S., \& Arruda, J. A. M. (2017). Neurotrauma: extensão realizada pelo núcleo de estudos acadêmicos em neurocirurgia. Ciência em Extensão, 13(3), 64-76. Recuperado de https://ojs.unesp.br/index.php/revista_proex/article/view/1422/1415.

Barr, R. G. (2014). Crying as a trigger for abusive head trauma: a key to prevention. Pediatric Radiology, 44 (S4), 559-564. DOI: 10.1007/s00247-014-3100-3.

Bardin, L. (2011). Análise de conteúdo. São Paulo: Edições 70, 2011, 229 p.

Christian, C. W., Block, R., American Academy of Pediatrics, \& Committee on Child Abuse and Neglect. (2009). Abusive Head Trauma in Infants and Children. Pediatrics, 123, 1409-1411. DOI: 10.1542/peds.2009-0408.

Conselho Estadual de Educação do Estado do Paraná. (2014). Processo No 1265/14. Normas e Princípios para a Educação Infantil no Sistema de Ensino do Estado do Paraná. http://www.cee.pr.gov.br/arquivos/File/pdf/Deliberacoes/2014/Del_02_14.pdf.Acess ado dia 21/08/2020.

Fernandes, V. M., Silva, N. L., \& Javorski, M. (2010). Prevenção da Síndrome do Bebê Sacudido: conhecimento da equipe de Saúde da Família. Nursing, 13, 304-8.

Foley, S., Kovács, Z., Rose, J., Lamb, R., Tolliday, F., Simons-Coghill, M., Stephens, A., Scheiber, D., Toma, A., Asbóth, K., Kassai, T., Agathonos, H., Lopes, N. R. L., Williams, L. C. A., Sahin, F., Tasar, A., \& Sarten, T. (2013). International collaboration on prevention of shaken baby syndrome - an ongoing project/intervention. Paediatrics and International Child Health, 33(4), 233-238. DOI: 10.1179/2046905513Y.0000000093.

Gordy, C., \& Kuns, B. (2013). Pediatric Abusive Head Trauma. Nursing Clinics of North America, 48, 193-201. DOI: 10.1016/j.cnur.2013.01.013.

Hennes, H., Kini, N., \& Palusci, V. (2001). Chapter Three: The Epidemiology, Clinical Characteristics and Public Health Implications of Shaken Baby Syndrome. Journal of Aggression, Maltreatment \& Trauma, 5 (1), 19-40. DOI: https://doi.org/10.1300/J146v05n01_03. 
Hinds, T., Shalaby-Rana, E., Jackson, A. M., \& Khademian, Z. (2015). Aspects of abuse: Abusive Head Trauma. Current Problems in Pediatric and Adolescent Health Care, 45, 71-79. DOI: 10.1016/j.cppeds.2015.02.002.

Le Roux-Kemp, A., \& Burger, E. (2014). Shaken Baby Syndrome: a South African medico-legal perspective. Potchefstroom Electronic Law Journal, 17(4), 1287-1316. Recuperado de https://ssrn.com/abstract $=2544367$.

Lopes, N. R. L. (2013). Trauma craniano violento: conhecimento parental e avaliação de material informativo [dissertação]. São Carlos: Programa de Pós-Graduação em Psicologia da Universidade Federal de São Carlos. Recuperado de https://repositorio.ufscar.br/handle/ufscar/6038?show=full.

Lopes, N. R. L., \& Williams, L. C. A. (2016). Avaliação do Conhecimento sobre Trauma Craniano Violento por Pais Brasileiros. Psicologia: Teoria e Pesquisa, 32(2). DOI: https://doi.org/10.1590/0102-3772e32223.

Narang, S., \& Clarke, J. (2014). Abusive Head Trauma: Past, Present, and Future. Journal of Child Neurology, 29(12), 1747-1756. DOI: 10.1177/0883073814549995.

Nuño, M., Ugiliweneza, B., Zepeda, V., Anderson, J. E., Coulter, K., Magana, J. N., et al. (2018). Long-term impact of abusive head trauma in young children. Child Abuse \& Neglect, 85, 39-46. DOI: 10.1016/j.chiabu.2018.08.011.

Parks, S., Sugerman, D., Xu, L., \& Coronado, V. (2012). Characteristics of non-fatal abusive head trauma among children in the USA, 2003 e 2008: application of the CDC operational case definition to national hospital inpatient data. Injury Prevention, 18(6), 392-398. DOI: 10.1136/injuryprev-2011-040234.

Runyan, D. K, \& Zolotor, A. (2009). The Period of PURPLE Crying: Keeping babies safe in North Carolina. In: Dodge KA, Coleman DL (Eds.), Preventing Child Maltreatment - Community Approaches. New York, The Guilford Press, 102-118.

Santana, S. M. S., Silva, E. S., Soares, J. P. R., Santana, M. C., \& Nery, F. S. (2017). Fatores Determinantes à Síndrome do Bebê Sacudido e suas Consequências. International Nursing Congress. Recuperado de https://eventos.set.edu.br/index.php/cie/article/view/5617/2065. 
Souza, P. B., Batista, A. P., \& Toni, C. G. S. (2018). Programa de Orientação Breve a Cuidadores de bebês: avaliação e formulação. PSI UNISC, Santa Cruz do Sul, 2(1), 105-121. Recuperado de https://online.unisc.br/seer/index.php/psi/article/view/11125.

Strouse, P. J. (2018). Shaken baby syndrome is real. Pediatric Radiology, 48(8), 10431047. Recuperado de https://link.springer.com/article/10.1007/s00247-018-4158-0.

Tolliday, F., Simons, M., Foley, S., Benson, S., Stephens, A., \& Rose, D. (2010). From inspiration to action: the Shaken Baby Prevention Project in Western Sydney. Communities, Children and Families in Australia, 5, 31-47. Recuperado de https://search.informit.com.au/documentSummary; $\mathrm{dn}=844167744001110$;res=IELH SS; type $=$ pdf.

Vieira, A. C. G, Milbrath, V. M., \& Moraes, A. C. (2006). "Sindrome do bebê sacudido"Relato de Experiência de acadêmicas de enfermagem. Enferm Atual, 6(36), 17-19. Recuperado de https://pesquisa.bvsalud.org/portal/resource/pt/bde-15589.

Vinchon, M. (2017). Shaken baby syndrome: what certainty do we have? Child'sNervous System, 33: 1727-1733. DOI: 10.1007/s00381-017-3517-8.

Submetido em: 26/04/2020

Aprovado em: 02/09/2020 